\title{
A TRANSPARÊNCIA COMO INSTRUMENTO DE ACOMPANHAMEN- TO DO PLANEJAMENTO ESTRATÉGICO PÚBLICO MUNICIPAL
}

\author{
TRANSPARENCY AS INSTRUMENT FOR MONITORING MUNICIPAL PUBLIC \\ STRATEGIC PLANNING
}

\author{
Vanessa Unfried Fenner \\ Universidade Federal da Fronteira Sul, RS, Brasil \\ E-mail: va.fenner@hotmail.com \\ Liara Laís Scheid \\ Universidade Federal da Fronteira Sul, RS, Brasil \\ E-mail: liarascheid@yahoo.com.br \\ Dionéia Dalcin \\ Universidade Federal da Fronteira Sul, RS, Brasil \\ E-mail:dioneia.dalcin@uffs.edu.br \\ Carlos Eduardo Ruschel Anes \\ Universidade Federal da Fronteira Sul, RS, Brasil \\ E-mail: carlos.anes@uffs.edu.br
}

Recebido em: 06.05.2019 - Aceito em: 27.08.2019

DOI: http://dx.doi.org/10.5902/2526629238024

\section{RESUMO}

O acompanhamento do planejamento estratégico é uma etapa fundamental para garantir o seu sucesso, seja nas organizações privadas ou no setor público. Para auxiliar no monitoramento dos planos estratégicos, as organizações, em especial as públicas, contam com a transparência como uma de suas ferramentas. É através dela que as informações acerca da gestão pública, isto é, das ações previstas pelo planejamento, são disponibilizadas à sociedade e esta, ao acessá-las, poderá cobrar o cumprimento das metas e objetivos traçados. Esse controle social auxilia os agentes públicos a realizar as correções, atualizações e mudanças de curso necessárias para atingir seus objetivos estratégicos com maior efetividade. Nesse sentido, este ensaio teórico tem como objetivo discutir o papel da transparência como instrumento do planejamento estratégico público municipal, em especial, na etapa de acompanhamento. Neste estudo, evidenciase o estágio de monitoramento dos planos estratégicos da administração pública. A partir da discussão, nota-se a importância dos mecanismos de transparência para o planejamento estratégico municipal, tendo em vista não somente o melhor 
funcionamento das instituições públicas, mas também o consequente aumento da qualidade de governança e da confiança no governo. Entende-se também que a transparência é promotora da participação dos cidadãos na gestão pública, o que favorece a efetividade das políticas públicas nesta elaboradas e implementadas e, consequentemente, impulsiona o desenvolvimento da sociedade.

PALAVRAS-CHAVE: Administração Pública; Acesso a informações; Políticas Públicas; Desenvolvimento; Municípios.

\section{ABSTRACT}

Monitoring strategic planning is a key step to ensure its success, whether in private organizations or in the public sector. To assist in monitoring strategic plans, organizations, especially public ones, rely on transparency as one of their tools. It is through this that the information about public management, that is, of the actions projected by the planning, are made available to the society. When accessing them, society can demand the fulfillment of the goals and objectives outlined. This social control helps public agents make corrections, updates and course changes necessary to reach their strategic objectives with greater effectiveness. In this sense, this theoretical essay aims at discussing the role of transparency as instrument of municipal public strategic planning, especially in the monitoring stage. In this study, the monitoring stage of the strategic plans of the public administration is evidenced. Our discussion shows the importance of transparency mechanisms to the municipal calculations, not only to improve the quality of public information, but also to increase quality of governance and trust in government. It is also understood that transparency promotes the participation of citizens in public management, which favors the effectivity of public policies and, as a consequence, promotes development to the society.

KEYWORDS: Public administration; Access to information; Public policy; Development; Municipalities.

\section{INTRODUÇÃO}

O planejamento estratégico não é um termo que figura há muito tempo e de forma ampla no setor público. À medida que a administração pública tornou-se mais aberta, adotando características como a participação social, passou-se a utilizar o planejamento estratégico. Segundo Pares e Valle (2006), o Estado que ouve e negocia com a sociedade organizada, com o setor privado e com outras esferas de governo e instituições demanda ferramentas fortes de planejamento 
em que diretrizes, objetivos e resultados se vinculam de forma transparente para o cumprimento das funções do setor público.

Não basta, no entanto, elaborar um plano para o bom funcionamento das instituições públicas. Acompanhar o cumprimento das metas e objetivos nele previstos é uma etapa indispensável para garantir a efetividade e o bom desempenho da gestão pública, seja na esfera federal, estadual ou municipal. Segundo Estrada e Almeida (2007), o acompanhamento serve não somente para medir, quantitativamente, os planos desenvolvidos, mas também para orientar e dar suporte às correções necessárias, que garantam o alcance da visão de futuro perseguida pelo planejamento estratégico.

Pretende-se, neste trabalho, realizar uma discussão teórica sobre a etapa de acompanhamento dos planos estratégicos da administração pública, evidenciando o papel da transparência pública nesse processo. Entende-se que o acompanhamento dos planos não somente é realizado pelos agentes públicos, mas também, em parte, pelos cidadãos que monitoram a gestão pública, por meio do acesso às informações sobre o planejamento e às ações implementadas com vistas à realização dos planos. O objetivo deste estudo, portanto, é discutir o papel da transparência como instrumento do planejamento estratégico público, em especial, em sua etapa de acompanhamento. Caracterizando-se como um ensaio teórico, artigos práticos e teóricos, bem como livros, auxiliaram na construção deste trabalho, resultante da disciplina Planejamento e Gestão Estratégica em Desenvolvimento, que integra a grade curricular do Mestrado em Desenvolvimento e Políticas Públicas da Universidade Federal da Fronteira Sul.

Para embasar essa discussão, apresentam-se conceitos e debates inerentes ao planejamento estratégico, ao planejamento estratégico no setor público com ênfase à esfera municipal e ao acompanhamento do planejamento. Por fim, discorre-se sobre o papel da transparência para o acompanhamento dos planos estratégicos desenvolvidos na esfera pública.

\section{PLANEJAMENTO ESTRATÉGICO}

O conceito de planejamento estratégico é composto pelas ideias de estratégia e planejamento. Essas, utilizadas inicialmente para técnicas militares, foram adaptadas para o ambiente empresarial na década de 1960 (Gonçalves, 2005).

O planejamento, segundo Drucker (1984), consiste na antecipação do futuro e, consequentemente, na redução das incertezas. Para isso, envolve o conheci- 
mento dos ambientes, tanto interno quanto externo, que interagem com a organização ou o local, onde o planejamento é elaborado e executado. Concordando com isso, Souza (2011, p. 46) afirma que:

[...] planejar sempre remete ao futuro: planejar significa tentar prever a evolução de um fenômeno ou, para dizê-lo de modo menos comprometido com o pensamento convencional, tentar simular os desdobramentos de um processo, com o objetivo de melhor precaver-se contra prováveis problemas ou, inversamente, com o fito de meIhor tirar partido de prováveis benefícios (Souza, 2011, p. 46).

Já a estratégia é definida, por Mintzberg et al. (2006), como plano ou padrão que integra metas, políticas e sequências de ação em um todo coeso. Para Chiavenato e Sapiro (2009), a estratégia é resultado do pensamento estratégico e consiste em um curso de ação para uma posição futura diferente da atual que poderá oferecer vantagens à organização.

Juntas, essas duas ideias formam o conceito de planejamento estratégico, definido como "um processo de formulação e execução de estratégias organizacionais para buscar a inserção da organização e de sua missão no ambiente onde ela atua" (Chiavenato \& Sapiro, 2009, p. 30). Para Drucker (1984), esse processo é contínuo e constituído por uma série de decisões que envolvem riscos e que, por isso, devem ser tomadas sistematicamente e com o maior conhecimento possível sobre o futuro. Ainda segundo o autor, é também composto pela organização das atividades necessárias à execução das decisões e medição dos seus resultados.

Outra definição de planejamento estratégico é dada por Cavalcanti (2008), que afirma que ele refere-se à análise de alternativas possíveis que são adotadas em longo prazo com a finalidade de alcançar os grandes objetivos das organizações que estão condicionados a metas e ações. Sua realização, conforme o autor, visa uma vantagem em longo prazo.

Apesar de, inicialmente, ter sido usado em empresas privadas, o processo de planejamento estratégico é válido para todos os tipos de organizações, incluindo também instituições não governamentais e públicas, sendo importante também para governos em todas as suas esferas e suas secretarias e ministérios (Pereira, 2010). Segundo Rezende (2008), é um recurso indispensável para o processo de tomada de decisão, estando relacionado com o sucesso das organizações privadas e com o êxito das organizações públicas. No setor privado, o uso da estratégia muitas vezes está relacionado à rivalidade e à concorrência nos mercados, enquanto que no setor público, pode ser entendida como "um meio pelo qual as organizações podem melhorar desempenho e fornecer melhores serviços” (Boyne \& Walker (2010, p. 185). 
Ao longo dos anos, mais exatamente desde 1980, a gestão estratégica passou a ser indispensável ao setor público, sendo hoje facilmente encontrada em muitos países e em diferentes esferas de governo (Johnsen, 2015). Da mesma forma, o planejamento estratégico tornou-se um instrumento comumente utilizado na administração pública e nas entidades e órgãos que a compõem.

\subsection{Planejamento estratégico no setor público}

A partir da década de 1990, marcada por uma crise econômica e pela reforma de estado, as organizações públicas passaram a adotar o planejamento estratégico para melhorar a eficácia e eficiência da administração pública, espelhando-se nas experiências, práticas e ferramentas do setor privado (Heyer, 2010). Seu uso obteve maior amplitude no setor público devido à possibilidade que dá as organizações de lidarem com as mudanças de ambiente, ao aumento da capacidade de pensar estrategicamente, a possibilidade de esclarecer e priorizar objetivos, a racionalizar a distribuição de recursos e coordenar o estabelecimento de objetivos estratégicos, de ações e de recursos (Joyce, 1999; Bryson, 2011).

Para Bryson (2011), o principal objetivo do planejamento estratégico em organizações públicas é o desenvolvimento de um pensamento estratégico que crie valor público. Para o autor, o foco do planejamento estratégico é encontrar o meIhor ajuste da organização com o ambiente externo. Joyce (1999) acrescenta que o planejamento estratégico pode ajudar a melhorar os resultados e a eficiência dos serviços públicos, uma vez que auxilia na identificação de oportunidades e ideias inovadoras. Ainda segundo a autora, o planejamento estratégico possibilita revisões e redesenho da estrutura, dos processos, do sistema de capacitação e de outros assuntos sensíveis à organização pública. Dessa forma, a realização do planejamento estratégico representa uma oportunidade de repensar a missão e os objetivos estratégicos de longo prazo, analisar os pontos de atenção do ambiente externo, observar as características do ambiente interno e ajustar a estratégia, isto é, pensar estrategicamente (Poister \& Streb, 1999).

Assim como as empresas privadas, as organizações do ambiente público encontram dificuldades com relação ao planejamento estratégico. Uma das questões que se apresenta como uma barreira para a aplicação do planejamento estratégico, na visão de Pinto (1982), é a descontinuidade administrativa e a fraqueza da autoridade planejadora em defender uma decisão. Outras dificuldades percebidas pelo autor são a necessidade de apoio político, as mudanças no contexto, o 
grau de interação da organização com o ambiente, o volume e qualidade das informações, a capacitação dos participantes e os fatores burocráticos que cercam a administração pública.

Assim como Pinto (1982), Ota (2014) identificou a rotatividade dos gestores como um dos desafios para o uso do planejamento estratégico em organizações do setor público. Segundo o autor, a rotatividade política da alta gestão faz parte do processo democrático. A volatilidade política, no entanto, que se altera conforme a situação no ambiente externo provoca constante mudança no direcionamento e contribui para a dissociação entre planejamento e execução.

Com os avanços nos estudos sobre planejamento estratégico, diversas tipologias de planejamento foram desenvolvidas, algumas delas buscando superar as dificuldades inerentes a aplicação da ferramenta no setor público. Um desses tipos é o Planejamento Estratégico Participativo (PEP), uma metodologia que permite à organização pública desenvolver e implementar de maneira disciplinada $e$ participativa, um conjunto de estratégias, decisões e assuntos fundamentais, não só para sua sobrevivência, mas para sua eficácia, efetividade e progresso (Souto-Maior et al., 2000).

Apesar de que, historicamente, o processo de planejamento caracterizou-se por ser centralizado mesmo quando o foco era o setor público, mais recentemente algumas experiências de políticas públicas têm levado em consideração a participação da população em sua construção (Corrêa, 2013). Tais políticas, e até mesmo processos de Planejamento Estratégico Participativo, podem ser visualizadas principalmente no planejamento municipal, esfera governamental em que são utilizados diversos instrumentos, que auxiliam não somente na sua formulação, mas também em seu acompanhamento, realizado pelos cidadãos. O Plano Plurianual (PPA), a Lei de Diretrizes Orçamentárias (LDO) e a Lei Orçamentária Anual (LOA), expostos no Quadro 1, constituem os principais instrumentos de planejamento em médio prazo, de acordo com a Constituição Federal de 1988, e são elaborados com a participação social.

O Plano Plurianual, segundo Dias (2006, p. 8), consiste em planejamento estratégico de médio prazo, que contém os programas, compostos por projetos e atividades, que o governo pretende realizar, ordenando suas ações e visando à consecução de objetivos e metas a serem atingidos nos quatro anos de mandato. A Lei de Diretrizes Orçamentárias apresenta-se como uma estrutura de planejamento desenvolvida em curto prazo, um instrumento de elaboração anual, tendo como principal objetivo a compatibilização orçamentária anual com o planejamen- 
to de longo prazo definido no PPA (Dias, 2006). Já Lei Orçamentária Anual é um instrumento que prevê as receitas e despesas que potencialmente serão realizadas no período de um ano (Andrade, 2005).

Além dos instrumentos considerados fundamentais, previstos na Constituição, Pfeifer (2000) aponta o Plano Diretor como uma importante ferramenta do planejamento municipal, e que também conta com a participação da população para sua elaboração. Segundo o Ministério das Cidades (2004, p. 13-14), a construção e elaboração do Plano Diretor de cada cidade devem servir para incentivar os municípios a avaliar e implantar todo o sistema de planejamento municipal. Nos termos do Estatuto da Cidade, o Plano Diretor é definido como o instrumento básico para orientar a política de desenvolvimento e de ordenamento da expansão urbana do município. O detalhamento dos procedimentos do Plano Diretor é definido na Lei Orgânica Municipal, outro mecanismo de suporte ao planejamento citado por Pfeifer (2000). Para Rezende e Guagliardi (2008), tanto o Plano Diretor quanto os demais instrumentos municipais de planejamento devem estar alinhados ao Planejamento Estratégico Municipal para o bom desempenho de todos. 
Quadro 1 - Instrumentos de planejamento municipal

\begin{tabular}{|c|c|c|}
\hline Instrumento & Definição & $\begin{array}{l}\text { Planejamento Estratégico Parti- } \\
\text { cipativo (PEP) }\end{array}$ \\
\hline $\begin{array}{l}\text { Plano Pluria- } \\
\text { nual (PPA) }\end{array}$ & $\begin{array}{l}\text { Plano de médio prazo, instituído por } \\
\text { lei, que contém as diretrizes, os ob- } \\
\text { jetivos e as metas das despesas de } \\
\text { capital e outras despesas desta decor- } \\
\text { rentes, para os programas de duração } \\
\text { continuada, a serem seguidos pela ad- } \\
\text { ministração pública municipal em um } \\
\text { período de quatro anos (Brasil, 1988). }\end{array}$ & \multirow{3}{*}{$\begin{array}{l}\text { la } \\
\text { O Estatuto da Cidade prevê em } \\
\text { seu art. } 44 \text { a realização de deba- } \\
\text { tes, audiências e consultas públi- } \\
\text { cas sobre as propostas do Plano } \\
\text { Plurianual, da Lei de Diretrizes } \\
\text { Orçamentárias e do orçamento } \\
\text { anual como condição obrigatória } \\
\text { para a aprovação dos mesmos } \\
\text { pela Câmara Municipal (ESTA- } \\
\text { TUTO DA CIDADE, 2002). Dessa } \\
\text { forma, o PEP integra, por exigên- } \\
\text { cia legal, os procedimentos utili- } \\
\text { zados para a elaboração tanto do } \\
\text { PPA quanto da LDO e da LOA. }\end{array}$} \\
\hline $\begin{array}{l}\text { Lei de Dire- } \\
\text { trizes Orça- } \\
\text { mentárias } \\
\text { (LDO) }\end{array}$ & $\begin{array}{l}\text { Lei que norteia a elaboração dos orça- } \\
\text { mentos anuais, a fim de adequá-los às } \\
\text { diretrizes, objetivos e metas da admi- } \\
\text { nistração pública estabelecidos no Pla- } \\
\text { no Plurianual. Compreende as priorida- } \\
\text { des do governo (despesas de capital) } \\
\text { para o exercício financeiro subsequen- } \\
\text { te, dispondo também sobre alterações } \\
\text { na legislação tributária e estabelecendo } \\
\text { a política de aplicação das agências fi- } \\
\text { nanceiras de fomento. (Brasil, 1988). }\end{array}$ & \\
\hline $\begin{array}{l}\text { Lei } \quad \text { Orça- } \\
\text { m e n t á r i a } \\
\text { Anual (LOA) }\end{array}$ & $\begin{array}{l}\text { É o instrumento de planejamento utili- } \\
\text { zado para gerenciar (fixar e estimar) as } \\
\text { receitas e despesas públicas, referentes } \\
\text { aos orçamentos fiscal, de seguridade so- } \\
\text { cial e de investimento, para cada exercí- } \\
\text { cio financeiro, e cujo conteúdo deve ser } \\
\text { compatível com o Plano Plurianual, com } \\
\text { a Lei de Diretrizes Orçamentárias e com } \\
\text { as normas da Lei de Responsabilidade } \\
\text { Fiscal (LRF) (Brasil, 1988). }\end{array}$ & \\
\hline Plano Diretor & $\begin{array}{l}\text { Instrumento básico da política de de- } \\
\text { senvolvimento do Município que visa } \\
\text { orientar a construção dos espaços } \\
\text { urbano e rural na oferta dos serviços } \\
\text { públicos essenciais, objetivando asse- } \\
\text { gurar melhores condições de vida para } \\
\text { a população (Brasil, 1988). }\end{array}$ & $\begin{array}{l}\text { Especialmente após a elaboração } \\
\text { do Estatuto da Cidade, o Plano } \\
\text { Diretor veio a integrar fatores po- } \\
\text { líticos, econômicos, financeiros, } \\
\text { sociais e territoriais. Tornou-se, as- } \\
\text { sim, um espaço de debate sobre } \\
\text { as estratégias de intervenção na } \\
\text { cidade, no qual a participação } \\
\text { direta dos cidadãos passou a } \\
\text { ser obrigatória, devendo ser esti- } \\
\text { mulada pelo poder público (ESTA- } \\
\text { TUTO DA CIDADE, 2002). A par- } \\
\text { ticipação direta da população nos } \\
\text { debates sobre a cidade, evidencia } \\
\text { a utilização do PEP no processo } \\
\text { de elaboração do Plano Diretor. }\end{array}$ \\
\hline
\end{tabular}

Fonte: Elaborado pelos autores (2019). 
O planejamento estratégico municipal, junto de seus instrumentos, pode constituir um instrumento de política pública relevante para o desenvolvimento local e regional (Rezende, 2006), devendo ser entendido como um processo contínuo, com constante retroalimentação e dinamismo, baseando-se na multidisciplinaridade e possibilitando a integração das áreas envolvidas (Hardt, Hardt \& Oba, 2003). Nesse sentido, Nogueira (2005), ao tratar do planejamento municipal, afirma que os diversos setores da sociedade devem estar em constante envolvimento com o planejamento público. Em contrapartida, o governo deve disponibilizar meios para que os cidadãos que tenham interesse no planejamento e no destino dado aos recursos tenham acesso às informações pertinentes a estes e, assim, sejam capazes de participar tanto de sua elaboração e execução quanto de seu acompanhamento.

\section{ACOMPANHAMENTO DOS PLANOS ESTRATÉGICOS}

Tanto no setor privado quanto no âmbito da gestão pública, e em qualquer uma de suas modalidades, o planejamento estratégico é um processo, sendo necessário, para sua realização, o seguimento de uma metodologia. Tal metodologia, segundo Certo e Peter (1993) e Mintzberg, Ahlstrand e Lampel (2000), pode ser dividida em cinco etapas - análise do ambiente, estabelecimento da diretriz organizacional; formulação das estratégias; implementação das estratégias e elaboração do controle estratégico.

O planejamento estratégico na gestão pública, para Lopes (1998), pode ser dividido em organização, elaboração do plano com base na análise do diagnóstico do município, implementação e monitoramento do programa de comunicação. Já para Pfeiffer (2000), essa metodologia pode conter as seguintes fases: preparação; análise do meio ambiente e da própria prefeitura; estruturação do plano por meio da visão, missão, estratégia e definição de objetivos; formulação dos projetos; formulação do plano; implementação e avaliação. Para Rezende e Castor (2006), os municípios também podem fazer seu planejamento estratégico utilizando uma metodologia dividida em dados do município, análises estratégicas municipais, diretrizes estratégicas municipais, estratégias e ações municipais, controles municipais e gestão do planejamento. Percebe-se que em todas as metodologias citadas, a presença da fase de monitoramento ou avaliação, que também pode ser compreendida como controle do plano ou controle estratégico, é indispensável para a efetivação do planejamento estratégico. 
A etapa de controle estratégico consiste em monitorar e avaliar todo o processo de planejamento estratégico, para melhorá-lo e assegurar um funcionamento adequado (Certo \& Peter, 1993; Mintzberg, Ahlstrand \& Lampel, 2000). Para Hunger e Wheelen (2002), e nesta etapa, as atividades corporativas e os resultados são acompanhados, de modo que o desempenho realizado possa ser comparado com o previsto. Com base nos resultados de desempenho, os gestores poderão ajustar a formulação e a implementação de sua estratégia, através das ações corretivas que forem necessárias (Estrada \& Almeida, 2007).

Para Certo e Peter (1993), o acompanhamento do plano estratégico é fundamental, seja para a realização de ajustes e atualizações, seja para a avaliação do cumprimento das metas que nele foram traçadas. Tratando-se do planejamento estratégico público, Pares e Valle (2006) afirmam que as atividades de monitoramento e avaliação assumem caráter estratégico, para conferir maior qualidade aos gastos públicos e otimizar a obtenção de resultados pelo setor público.

A obtenção de melhores resultados decorre da possibilidade de revisar o planejamento, utilizando informações as quais não se possuía acesso anteriormente, e, assim, atualizá-lo e adaptá-lo às mudanças que ocorreram desde sua elaboração inicial. Essa atualização é necessária na maioria dos planejamentos, uma vez que a racionalidade envolvida nos processos decisórios que o compõem é limitada. Segundo Simon (1979), tal limitação decorre da restrição dos conhecimentos do decisor e de valores e conceitos que o influenciam na tomada de decisão.

Alguns instrumentos que auxiliam no acompanhamento do planejamento estratégico, já utilizados por empresas privadas, passaram a ser adotados também por algumas organizações públicas, buscando melhorar as práticas de gestão a fim de serem eficientes na prestação de serviços (Silva \& Gonçalves, 2011). Um deles é o Balanced Scorecard (BSC), método desenvolvido por Kaplan e Norton, no início da década de 1990, que tem como objetivo resolver problemas de monitoramento do desempenho das estratégias implantadas. O BSC traduz a missão e a visão em objetivos e iniciativas (Kaplan \& Norton, 2001 apud Silva \& Gonçalves, 2011). Outros exemplos são o Método Grumbach - que agrega as ferramentas básicas de planejamento estratégico à metodologia de cenários prospectivos, permitindo assim o gerenciamento de médio e longo prazo - e o método de Gerenciamento Pelas Diretrizes (GPD), ou ciclo PDCA, que "aborda o planejamento (estabelecimento das diretrizes e metas), execução dos planos de ação, monitoramento dos resultados alcançados e análise dos desvios entre estes e as metas propostas" (Silva \& Gonçalves, 2011, p. 469). 
Outra ferramenta útil ao acompanhamento dos planos estratégicos desenvolvidos no setor público é a transparência. Além do acompanhamento realizado pelos gestores e agentes públicos responsáveis pelo planejamento municipal, o controle dos planos estratégicos também pode ocorrer por meio do envolvimento dos cidadãos. Diversos dispositivos legais - como a Constituição Federal de 1988, especificamente nos artigos 165 a 169 (leis orçamentárias), as Constituições Estaduais, a Lei Federal 4.320/64, a Lei Complementar n. ${ }^{\circ} 101$ de 04 de maio de 2000 (Lei Responsabilidade Fiscal - LRF), a Lei Orgânica, o Plano Diretor, os Planos Plurianuais e o Orçamento Participativo -, além de regularem a elaboração do planejamento no setor público, servem como instrumentos de controle e avaliação desses. Através da disponibilização de documentos, imposta por tais leis e por outras que determinam a transparência pública, não somente os agentes públicos e gestores podem acompanhar e avaliar o plano estratégico, mas também a população tem a oportunidade de verificar se metas e objetivos traçados estão sendo perseguidos e se as atividades desempenhadas para esse fim seguem os princípios, éticos e morais, da administração pública, buscando benefícios reais para a sociedade. Em outras palavras, a participação da população no acompanhamento do planejamento estratégico público se dá através da transparência.

\section{O PAPEL DA TRANSPARÊNCIA NO CONTROLE DO PLANEJAMENTO}

O planejamento estratégico público deve ser amplamente divulgado para facilitar sua aceitação e sucesso. A não divulgação e a falta de organização podem resultar em fracasso, pois o planejamento é uma atividade coletiva e participativa entre as pessoas que compõem a entidade autora dele e, eventualmente, do meio ambiente externo, composto pelos cidadãos e pelo setor privado (Rezende, 2008).

Enquanto, nas organizações privadas, a abertura de informações é uma indicação de boa prática de gestão, nas organizações públicas, caracterizadas por maior permeabilidade a pressões e controles externos, a prestação de contas é uma obrigação legal (Boyne, 2002). A transparência é uma obrigatoriedade da gestão pública e um direito de todo cidadão. Imposta inicialmente pela Lei de Responsabilidade Fiscal e ampliada pela Lei da Transparência e pela Lei de Acesso à Informação, busca atender ao princípio da Publicidade da Administração Pública. O princípio da Publicidade determina que os atos da gestão pública devem ser transparentes e, portanto, todas as suas ações devem ser divulgadas oficialmente para conhecimento público, exceto nas hipóteses de sigilo previstas na Constituição. 
A ampliação no acesso às informações por parte dos cidadãos fez com que as organizações públicas fossem fortemente estimuladas a adotar práticas com foco no cidadão, na melhoria do desempenho e da transparência da gestão administrativa e na melhoria da qualidade dos serviços públicos (Camargo, 2016). Nesse sentido, tratando-se de organizações do setor público, a transparência mostra-se como um elemento útil, não somente à elaboração do planejamento estratégico, mas também ao seu acompanhamento. A transparência está intimamente relacionada à medição eficaz do desempenho, um dos principais aspectos do planejamento dentro dos governos (Melkers \& Willoughby, 2005).

Além disso, uma maior transparência promove a legitimidade das decisões tomadas, possibilitando, de maneira mais efetiva, a implementação das ações definidas no planejamento estratégico. A eficácia e a legitimidade da atuação pública encontram apoio na qualidade da interação entre diferentes níveis de governo, organizações empresariais e sociedade civil (Oliveira, 2008).

A transparência é, dessa forma, um importante mecanismo de aproximação e interação entre setor público, setor privado e sociedade, não devendo ser concebida apenas como uma obrigação formal, mas também como um elemento necessário para dar legitimidade às decisões do administrador (Campos, Paiva \& Gomes, 2013). Para o Centro Regional de Estudos para o Desenvolvimento da Sociedade da Informação - CETIC - (2017), muito mais que priorizar uma melhor qualidade da gestão e dos próprios serviços públicos, inicia um "movimento para democratizar o acesso a informação e ampliar o debate e a participação popular na construção da agenda de políticas públicas" (CETIC, 2017, p. 27).

Essa relação, entre a transparência e a legitimidade das decisões tomadas no âmbito da administração pública, tem sua base na governança pública. Seus princípios (transparência, integridade e accountability) visam contribuir para a melhoria da transparência e do controle sobre o desempenho da gestão (Silva et al., 2011).

Através da transparência e de seus instrumentos legais, a organização pública também sofre maior vigilância de suas ações e é cobrada para ter coerência com decisões passadas (Motta, 2001). Dessa forma, a promoção da transparência "contribui para a redução das incertezas de investimento, proporcionando uma forma de controle sobre a conduta dos agentes públicos no sentido da maior eficiência possível dos resultados" (Filgueiras, 2011, p. 76-77). Em consonância, Amaro et al. (2008) assegura que a falta de transparência governamental facilita a corrupção, surgindo, como um dos reflexos, a falta de credibilidade da sociedade em seus governantes e o afastamento desta da política. 
A eficiência dos resultados também é destacada por Reis e Venâncio (2016) em uma análise sobre o Plano Diretor municipal, uma das ferramentas legais do planejamento estratégico. As autoras afirmam que a participação popular tanto na elaboração quanto na fiscalização do plano diretor é um importante mecanismo de orientação e fiscalização da atuação estatal e, por isso, implica no planejamento das políticas públicas de forma mais eficiente e condizente com a realidade social.

Llewellyn (1998) e Llewellyn e Tappin (2003) apontam também a importância da transparência para a aquisição de recursos. Segundo elas, as organizações do setor público, ao criarem metas e gerarem resultados mais transparentes, podem garantir financiamento de órgãos governamentais.

Para Castro (2011), se considerada no planejamento, a transparência colaborará para o sucesso dos resultados das organizações públicas, à medida que fortalece o controle, fase do planejamento estratégico que garante que os objetivos da administração pública sejam alcançados e as ações conduzidas de forma econômica, eficiente e eficaz. Consequentemente, também poderá contribuir significativamente para a qualidade de governança e para o aumento da confiança no governo e em suas instituições.

Nesse sentido, considerando que transparência constitui um importante elemento que pode contribuir significativamente no processo do planejamento estratégico municipal e, em especial, em sua fase de monitoramento, Bryson (2011) acredita que a transparência deve ser vista como uma questão estratégica a ser tratada como parte do desenho do processo de planejamento estratégico, ou do próprio plano estratégico. Para o autor, a transparência deveria se tornar o modo padrão de operação para a maioria dos governos, criando uma cultura de transparência que leve a práticas de planejamento estratégico mais participativas e colaborativas.

\section{CONSIDERAÇÕES FINAIS}

É imprescindível não somente elaborar e implementar o planejamento estratégico, mas realizar seu acompanhamento a fim de evitar erros e corrigir seus rumos. Permitir a colaboração da sociedade, disponibilizando e facilitando o acesso a informações sobre a gestão municipal - não apenas aquelas que são obrigatoriedades previstas em lei -, torna-se fundamental nesse processo. Percebe-se assim, que a transparência assume um importante papel na gestão pública participativa, especialmente no que se refere ao desenvolvimento do planejamento estratégico público. 
A efetiva participação da população na administração pública permite à gestão conhecer os anseios da sociedade e, dessa maneira, auxiliar na elaboração e implementação de políticas públicas alinhadas com a vontade popular, capazes de suprir suas reais necessidades. Uma maior legitimidade das decisões dos agentes públicos também é gerada pela interação entre governo e cidadãos, mediada pela transparência. Além disso, o envolvimento dos cidadãos nas ações das gestões públicas contribui com melhorias na qualidade da decisão e das políticas desenvolvidas, e ainda, atua a favor do fortalecimento da democracia.

Nesse sentido, para que se concretize, é preciso superar alguns entraves culturais que dificultam a participação popular, e encontrar meios de promover o interesse dos cidadãos em usufruir dos mecanismos de transparência pública para realizar o acompanhamento dos planos estratégicos elaborados na gestão pública. A efetivação da participação da população nas decisões públicas, apesar de crescente, ainda implica em uma mudança de paradigma na atuação dos governos municipais, pois exige esforços tanto da população quanto do poder público, que precisam aprender a atuar de maneira conjunta, unindo esforços para o alcance dos objetivos públicos (Millon, 2010). Faz-se necessária construção de uma nova cultura, que renuncie as estruturas sociais e culturais historicamente arraigadas e ainda existentes que se caracterizam pelo paternalismo, favoritismo, clientelismo e pela falta de prática de participação (Ribeiro, 2007).

Com uma nova perspectiva cultural, marcada por maior proximidade entre população e governos e maior interesse popular em exercer participação na gestão pública e no controle de suas atividades, políticas públicas mais efetivas podem ser implementadas, solucionando problemas sociais que colaborem para o crescimento econômico e para o desenvolvimento. Entende-se, dessa maneira, que a transparência no setor público trata-se de uma cooperação entre sociedade e governo e contribui, mesmo que indiretamente, para a promoção do desenvolvimento.

\section{REFERÊNCIAS}

Amaro, R. G et al. (2008). Uma discussão sobre a criação de indicadores de transparência na gestão pública federal como suporte ao ciclo da política pública. Revista de Contabilidade do Mestrado em Ciências Contábeis da UERJ, 13(2), 15-29.

Andrade, N. A. (2005). Planejamento Governamental para Municípios: Plano Plurianual, Lei de Diretrizes Orçamentárias e Lei Orçamentária Anual. São Paulo: Atlas. 
Boyne, G. A. (2002). Public and Private Management: What's the difference?. Journal of Management Studies, 39(1), 97-122.

Boyne, G. A. \& Walker, R. M. (2010). Strategic Management and Public Service Performance: The Way Ahead'. Public Administration Review, 70, 185-192.

Brasil. (1988). Constituição da República Federativa do Brasil. Recuperado de http://www.planalto.gov.br/ccivil_03/Constituicao/Constituicao.htm.

Bryson, J. M. (2011). Strategic planning for public and nonprofit organizations: a guide to strengthening and sustaining organizational achievement. (4. ed.). San Francisco: JosseyBass Publishers.

Camargo, A. (2016). Engajamento, Participação e Transparência como Meios para alcançar a Democracia Digital: o Potencial do uso da Internet. Revista Comunicação - Reflexões, Experiências, Ensino, 11(11), 77-89.

Campos, R; Paiva, D; Gomes, S. (2013, Maio/Agosto). Gestão da informação pública: um estudo sobre o Portal Transparência Goiás. Revista Sociedade e Estado, 28(2), 421-446.

Castro, D. P. (2011). Auditoria, Contabilidade e Controle Interno no Setor Público. (4. ed.). São Paulo: Atlas.

Cavalcanti, F. A. (2008). Planejamento Estratégico participativo: concepção, implementação e controle de estratégias. São Paulo: Editora Senac São Paulo.

Centro de Estudos sobre as Tecnologias da Informação e da Comunicação. (2017). Pesquisa Sobre o Uso das Tecnologias de Informação e Comunicação no Setor Público Brasileiro: TIC Governo Eletrônico 2017. São Paulo: Comitê Gestor da Internet no Brasil, p. 440. Recuperado de https://cetic.br/media/ docs/publicacoes/2/TIC_eGOV_2017_livro_eletronico.pdf.

Certo, S. C., \& Peter, J. P. (1993). Administração Estratégica: planejamento e implementação da estratégia. São Paulo: Makron Books.

Chiavenato, I., \& Sapiro, A. (2009). Planejamento estratégico. (2. ed.). Rio de Janeiro: Elsevier.

Corrêa, J. C. S. (2013). O plano estratégico de desenvolvimento regional e suas interfaces com a consulta popular no COREDE Alto Jacuí, no período de 2009 a 2012 (Dissertação de Mestrado), Universidade de Santa Cruz do Sul, Santa Cruz do Sul. Recuperado de https://repositorio.unisc.br/jspui/ handle/11624/574.

Dias, O. P. (2006). Planejamento/Orçamento Público (PPA, LDO E LOA) e Controle Orçamentário. Porto Velho: TCRO.

Drucker, P. (1984). Introdução a Administração. São Paulo: Pioneira. 
Estatuto da cidade. (2002). Guia para implementação pelos municípios e cidades. (2. ed.) Brasília: Câmara dos Deputados, Coordenação de Publicações.

Estrada, R. J. S; Almeida, M. I. R. (2007, Setembro). A eficiência e a eficácia da gestão estratégica: do planejamento estratégico à mudança organizacional. Revista de Ciências da Administração, 9(19), 147-178. Recuperado de https://periodicos.ufsc.br/index.php/adm/article/view/1784.

Filgueiras, F. (2011). Além da transparência: accountability e política de publicidade. Revista Lua Nova, 84, 353-364. Recuperado de http://www.scielo.br/ scielo.php?pid=S0102-64452011000300004\&script=sci_abstract\&tIng=pt.

Gonçalves, R. G. (2005). Modelos emergentes de planejamento: elaboração e difusão (Tese de Doutorado), Universidade Federal do Rio de Janeiro, Rio de Janeiro. Recuperado de https://jacksondetoni.files.wordpress.com/2012/09/ texto-5-tese-pes-ipur-raquel5.pdf.

Hardt, L. P. A; Hardt, C.; Oba, L. T. (2003). Planejamento do desenvolvimento urbano sustentável: position paper. In: Seminário Internacional em Gestão Urbana. Curitiba: PUC-PR.

Heyer, G. (2010). New public management: A strategy for democratic police reform in transitioning and developing countries. Policing: An International Journal of Police Strategies \& Management, 34(3), 419-433.

Hunger, J. D; Wheelen, T. L. (2002). Gestão Estratégica: princípios e prática. Rio de Janeiro: Reichmann \& Affonso.

Johnsen, A. (2015, Agosto). Strategic Management Thinking and Practice in the Public Sector: A Strategic Planning for All Seasons, Financial Accountability \& Management, 31.

Joyce, P. (1990). Strategic Management for the public services: Managing The Public Service. Open University Press.

Llewellyn, S. (1998). Boundary work: costing and caring in the Social Services. Accounting. Organizations and Society, 23(1), 23-47.

Llewellyn, S; Tappin, E. (1998, Junho). Strategy in the Public Sector: Management in the Wilderness. Journal Of Management Studies, 40(4), 955-982.

Lopes, R. (1998). A cidade intencional: o planejamento estratégico de cidades. Rio de Janeiro: Mauad.

Melkers, J; Willoughby, K. (2005). Models of Performance-Measurement Use in Local Governments: Understanding Budgeting, Communication, and Lasting Effects. Public Administration Review, 65(2), 180-190.

Millon, L. V. (2010). Participação Popular nas Políticas Públicas Municipais: eficácia e implementação. Revista de Direito, 13(17), 59-71. 
Ministério Das Cidades. (2004). Plano Diretor Participativo: guia para elaboração pelos municípios e cidadãos. Brasília.

Mintzberg, H; Lampel, J; Quinn, J. B; Ghoshal, S. (2006). O processo da estratégia: conceitos, contextos e casos selecionados. (4. ed.). Porto Alegre: Bookman.

Mintzberg, H., Ahlstrand, B., \& Lampel, J. (2000). Safári de estratégia: um roteiro pela selva do planejamento estratégico. Porto Alegre. Bookman.

Motta, C. C. P. (2001). Gestão fiscal: e resolutividade nas licitações. Belo Horizonte: Del Rey.

Nogueira, M. A. (2005). Um Estado para a sociedade civil: temas éticos e políticos da gestão democrática. (2. ed). São Paulo: Cortez.

Oliveira, G. J. (2008). Governança pública e parcerias do estado: a relevância dos acordos administrativos para a nova gestão pública. Âmbito Jurídico, Rio Grande, 58.

Ota, E. T. (2014). Os desafios para o uso do planejamento estratégico nas organizações públicas: uma visão de especialistas (Dissertação de Mestrado), Fundação Getulio Vargas, Rio de Janeiro. Recuperado de http://bibliotecadigital.fgv.br/dspace/handle/10438/11825.

Pares, A; Valle, B. A retomada do planejamento governamental no Brasil e seus desafios. In Giacomoni, J; Pagnussat, J. L. (Orgs.). (2006). Planejamento e orçamento governamental. Brasília: ENAP.

Pereira, M. F. (2010). Planejamento Estratégico: teorias, modelos e processos. São Paulo: Atlas.

Pfeiffer, P. (2000). Planejamento estratégico municipal no Brasil: uma nova abordagem. Brasília: ENAP.

Pinto, A. L. (1982, Junho). O Planejamento Estratégico na Administração Pública Brasileira: rumos e perspectivas. Cadernos FUNDAP, 2(4), 4-13.

Poister, T. H., \& Streib, G. D. (1999). Strategic management in the public sector: Concepts, models, and processes. Public Productivity \& Management Review, 23, 308-325.

Reis, E. V. B; Venâncio, S. R. (2016). O direito à cidade e a participação popular no planejamento urbano municipal. Direito e Desenvolvimento, 7(2), 222-247. Recuperado de https://www.e-publicacoes.uerj.br/index.php/rdc/article/view/23060.

Rezende, D. A. (2006), Julho/Dezembro). Planejamento estratégico municipal como proposta de desenvolvimento local e regional de um município paranaense. Revista da Fae, 29, 87-104. Recuperado de https://revistafae.fae. edu/revistafae/article/view/368. 
Rezende, D. A. (2008). Planejamento Estratégico para organizações privadas e públicas: guia prático para elaboração do projeto de plano de negócios. Rio de Janeiro: Brasport.

Rezende, D. A; Castor, B. V. J. (2006). Planejamento estratégico municipal: empreendedorismo participativo nas cidades, prefeituras e organizações públicas. (2. ed). Rio de Janeiro: Brasport.

Rezende, D. A., \& Guagliardi, J. A. (2008, Setembro/Dezembro). Planejamentos municipais, gestão de prefeituras e tecnologia da informação: estudos de casos em pequenos municípios paranaenses. Revista de Ciências da Administração, 10(22), 186-211. Recuperado de https://periodicos.ufsc.br/index. php/adm/article/view/2175-8069.2008v10n22p186.

Ribeiro, S. P. (2007, Agosto). Participação popular na gestão pública: quais as armadilhas e quais os caminhos?. III Jornada Internacional De Políticas Públicas, São Luís: PPGPP.

Silva, F. A; Gonçalves, C. A. (2011, Setembro/Dezembro). O Processo de formulação e implementação de Planejamento Estratégico em instituições do setor público. Revista de Administração da UFSM, 4(3), 458-476. Recuperado de https://periodicos.ufsm.br/reaufsm/article/view/3833.

Silva et al. (2011). Princípios da Governança no Setor Público: Um Estudo no Tribunal de Contas do Estado do Ceará. XXXV Encontro da ANPAD. Rio de Janeiro: ANPAD.

Simon, H. A. (1979). Comportamento administrativo: estudo dos processos decisórios nas organizações administrativas. Rio de Janeiro: Fundação Getúlio Vargas.

Souto-Maior, J. et al. (2000). Planejamento estratégico participativo em uma ONG. Estudos Avançados em Administração. Editora Ideia.

Souza, M. L. (2011). Mudar a cidade: uma introdução crítica ao planejamento e à gestão urbanos. (8. ed.). Rio de Janeiro: Bertrand Brasil. 